\title{
The Relationship Between Indonesian Remigrants' Psychological Well-Being and Hardiness
}

\author{
$1^{\text {st }}$ Pradipto, Y.D. ${ }^{1}, 2^{\text {nd }}$ Azizah, A. ${ }^{2}, 3^{\text {rd }}$ Maharani C.N. ${ }^{3}, 4^{\text {th }}$ Afina N. ${ }^{4}, 5^{\text {th }}$ Purnamasari S. ${ }^{5}, 6^{\text {th }}$ \\ Taufiq, R. ${ }^{6}$ \\ \{ypradipto@binus.edu1 ${ }^{1}$, rohmat.taufiq@umt.ac.id $^{6} ;$ rohmat.taufiq@binus.ac.id $\left.^{6}\right\}$
}

Psychology Department, Faculty of Humanities, BINUS University, Indonesia ${ }^{1}$, Informatic engineering

Department, Engineering Faculty, Muhammadiyah University, Tangerang, Indonesia ${ }^{2,3,4,5,6}$, Scholar of Doctor of Computer Science, BINUS Graduate Program, Bina Nusantara University, Jakarta, Indonesia ${ }^{6}$

\begin{abstract}
Over the years, there has been an increase in the number of Indonesian citizens migrating to different parts of the world. Migration is the process whereby people move from one part of the world to another in order to take up permanent or semi-permanent residence. Semi-permanent residence indicates that these immigrants might someday return back to their country of origin. Several studies have shown that there are significant differences in the psychological well-being and hardiness in migrants. Psychological well-being is a concept that includes many dimensions of quality of life such as subjective, social and psychological dimensions that can be measured using Ryff Scales of Psychological well-being (1995) [11]. Whereas hardiness emerged from an existential theory of personality that was developed by Kobasa (1979). Within this study it has been found that psychological well-being and hardiness are positively correlated $(\mathrm{r}=.617, \mathrm{p}<.01)$. However, there is no significant difference between participants living abroad and their scores on psychological well-being as well as hardiness.
\end{abstract}

Keywords: Indonesian remigrants; Psychological well-being; Hardiness

\section{Introduction}

As we enter the twenty-first century, there has been an increase in the number of Indonesian citizens migrating to other countries, either for work or education. Minister of Foreign Affairs of Indonesia, Retno L.P. Marsudis, has declared that about 4.3 million Indonesia citizens are living in another country by the year 2015 [7]. The migrants are usually in their productive age, in which according to Badan Pusat Statistik Indonesia, ranges from 15-64 years old. Usually productive age is characterized by an individual's effort to start and develop their career goals, which serve as one of the characteristics found in early adulthood that ranges between the age of 17-40 [13].

Migration is the movement of people from one place in the world to another for purpose of taking up permanent or semi-permanent residence, usually across a political boundary [8]. Most migrants have encountered discrimination and oppression at some time. Historically, they have been denied opportunities either due to the color of their skin, the accent in which they speak in, or the clothing they wear [14]. Studies have found that this act of discrimination was related to 
psychological functioning of Chinese adolescent immigrants [5]. Other studies have also shown that first-generation immigrant adolescents experience less positive well-being, meanwhile firstgeneration immigrant youth will experience higher level of positive well-being than the native-born $[2]$.

In their adjustment process, stress could be produced due to the fact that they have to adapt to a new culture that has different ways of functioning [4]. However, the stress experienced by these migrants can be counteracted by their ability to adapt to the host culture. According to [6], hardiness serves as a factor that can have an impact on the successful adaptation of migrants. It is indicated by Kobassa in [9] that hardiness measures one's commitment towards life goals, a sense of being in control with one's surrounding and experience challenge as a means towards change. It serves as a skill that can facilitate one's perception, evaluation and coping strategies which are necessary for successful resolution towards stressful events. It has been found that hardiness serves as a factor that brings positive outcomes for Chinese, Japanese, Filipino and Korean migrants in the USA. Studies have also shown that the first-generation migrants had a lower hardiness score than secondgeneration [6]. Thus, those who are able to adapt to the host culture would have a better sense of well-being than those who have difficulty in adapting.

However, most of these migrants are not all bound to remain in those countries, there comes a time when they have to return to their country of origin [8]. This is known as return migration and the individuals are called remigrants. Return migration occurs for several reasons such as (1) demand from family members [17], (2) to spend money in their own country, (3) to get appreciated for their abilities and skills and (4) obtain higher wages with lower living cost [1]. The view that is held by their country of origin would affect their quality of life. In Indonesia, living abroad for necessities such as work or education is something that brings pride and success for an individual.

As these individuals acquire higher level of knowledge, these remigrants have achieved qualifications for developing new technologies [10].

The quality of life experienced by these remigrants can bring about variations in their psychological well-being. By using an indigenous psychology approach, we are able to understand how the re-adjustment process can influence people based on the context of their original culture. The culture that was recently adapted would be brought back to the country of origin and their interaction will have an effect on returned migrants' psychological well-being and hardiness.

Psychological well-being is a concept that includes many dimensions of quality of life such as subjective, social and psychological dimensions, that can be measured by Ryff Scales of Psychological well-being, that consist of self-acceptance, positive relations with others, autonomy, environmental mastery, purpose in life, and personal growth [12]. Whereas hardiness emerged from an existential theory of personality that was developed by Kobasa in 1979. According to Kobasa, hardiness is a cluster of personality characteristics that comprises of 3 dimensions commitment, control, and challenge [9].

Existing studies have found that hardiness is associated with a greater level of psychological well-being

The aim of this study is to: (1) examine the relationship between psychological well-being and hardiness (2) to find out whether a difference exists between psychological well-being and hardiness possessed by Indonesian remgirants and Indonesian citizens group and (3) examine the factors that can affect psychological well-being and hardiness among Indonesians. 
The term hardiness was first coined by Kobasa in 1979 as a cluster of personality characteristics that comprises of 3 different dimensions (1) commitment, (2) challenge and (3) control [9]. According to Kobasa in [9], hardiness is believed to be an act of resistance against life stressors. In several studies, its components were found to contribute in psychological well-being. individuals high on hardiness have the ability to influence the outcome of their life events and try to learn something new out of their experiences. Whereas individuals low on hardiness are more likely to withdraw themselves from experiences that seems threatening [3].

The authors believe that the quality of life one has can affect an individual's tendency to accept new experiences and to evaluate them in a positive / negative light. As previously mentioned, psychological well-being is a concept that includes dimensions of the quality of life. Hence, it is suspected that psychological well-being and hardiness has a relationship.

Thus, the dimensions of psychological well-being contains the characteristics found in hardiness. Several studies has found hardiness components to be a contribution to well-being. The authors suspect that psychological well-being holds the different compartments in which these characteristics are fostered. With Indonesian remigrants possessing different level of psychological well-being compared to Indonesian citizens who haven't lived abroad, the author expects different scores on the relationship between psychological well-being and hardiness found in these two different groups.

\section{Method}

Demographic Schale including age, gender, domicile, employment status, job and educational experience, international experience, the length of time they spent living abroad as well as the reason to as why they have lived abroad becomes a demographic scale that represents the Indonesian population.

The instrument of Psychological well-being scale was adapted to fit into the Indonesian population such that each item was translated into Bahasa Indonesia. Pilot study was conducted to test the reliability of the measuring instrument such that Cronbach's alpha obtained was $0.89(\mathrm{M}=$ 177.77, $\mathrm{SD}=20.73$ ). Despite the relatively high reliability, authors' obtained a feedback from those who have filled out the questionnaire in which the participant believes that this scale contained many negative statements such that decision about the degree of agreement was hard to define.

In line with the psychological well-being, hardiness scale was also adapted to fit into the Indonesian population such that each item was translated into Bahasa Indonesia. Pilot study was conducted to test the reliability of the measuring instrument such that Cronbach's alpha obtained was $0.60(\mathrm{M}=3.90, \mathrm{SD}=4.02)$.

Participants were early adults within the age range of 17-40 living in area of Greater Jakarta or Jabodetabek. Early adulthood is characterized by the effort of an individual to start and develop career goals [13]. In addition, according to Bingham \& Stryker (1995), during socioemotional development, different types of personality develops throughout different ages. 


\section{Results}

The demographic results from this study were obtained from the data of 100 respondents. It is comprised of 48 male participants and 52 female participants out of which $56.1 \%$ of these participants live in Jakarta, 3.1\% in Bogor, 7.1\% in Depok, 16.3\% in Tangerang, 15.3\% in Bekasi and $1.0 \%$ lives in both Jakarta/Tangerang. In order to make a comparison between psychological well-being and hardiness among Indonesians, 50 participants never have had an international experience whereas the other 50 participants have had an international experience where they have at least stayed abroad for more than 4 weeks. There are at least 6 participants who have lived abroad for 1 year, 6 who have lived for 2 years and 14 participants have lived abroad for 3 or more years. Meanwhile, the rest (24 participants) have at least lived abroad around a period of 1 month to a year. The results indicate that the respondents have met the requirement needed to fulfil the study's objective and were adequate representative of the population being studied.

Participants in this study were 50 people with international experience $(\mathrm{M}=177.76, \mathrm{SD}=$ $18.83)$ and 50 people with no international experience $(\mathrm{M}=177.40, \mathrm{SD}=24.24)$. Levene's test indicated that there is a significant equality of variance $(F=3.91, p>.05)$. Hence, the first coloumn of values are used in order to analyze the t-test. An Independent sample t-test revealed that there is no statistically significant difference between people with international experience and people with no international experience on psychological well-being $(\mathrm{t}=.083, \mathrm{df}=98, \mathrm{p}>.05)$. This finding does not support the second hypothesis, thus, it was rejected.

Participants in this study were 50 people with international experience $(\mathrm{M}=3.32, \mathrm{SD}=3.58)$ and 50 people with no international experience $(\mathrm{M}=4.26, \mathrm{SD}=4.68)$. Levene's test indicated that there is a significant equality of variance $(F=2.43, \mathrm{p}>.05)$. Hence, the first coloumn of values are used in order to analyze the t-test. An Independent sample t-test revealed that there is no statistically significant difference between people with international experience and people with no international experience on hardiness $(\mathrm{t}=-1.128, \mathrm{df}=98, \mathrm{p}>.05)$. This finding does not support the second hypothesis, thus, it was rejected.

Participants in this study were 48 men $(M=183.13, S D=24.14)$ and 52 women $(M=172.46$, $\mathrm{SD}=17.67)$. Levene's test indicated that there is a significant equality of variance $(\mathrm{F}=3.31, \mathrm{p}>$ $.05)$. Hence, the first coloumn of values are used in order to analyze the t-test. An Independent sample t-test revealed that there is no statiscally significant difference between men and women on psychological well-being $(\mathrm{t}=1.80, \mathrm{df}=98, \mathrm{p}>.05)$.

Participants in this study were 48 men $(\mathrm{M}=4.56, \mathrm{SD}=4.53)$ and 52 women $(\mathrm{M}=3.08, \mathrm{SD}=$ 3.72). Levene's test indicated that there is a significant equality of variance $(F=6.66, p>.05)$. Hence, the first coloumn of values are used in order to analyze the t-test. An Independent sample ttest revealed that there is no statistically significant difference between men and women on hardiness $(\mathrm{t}=2.53, \mathrm{df}=98, \mathrm{p}>.05)$.

\section{Discussions}

Despite the relatively low reliability on hardiness scale (Cronbach's alpha obtained was 0.60, $\mathrm{M}=3.90$, SD (4.02), there is a positive correlation that exists between psychological well-being and 
hardiness $(\mathrm{r}=.617, \mathrm{p}<.01)$. The relatively low reliability on hardiness scale might be due to the fact that this scale has been adapted by transforming English statements into Bahasa Indonesia based on one fluent English native speaker's translation. Nevertheless, the significant correlation supports the author's first hypothesis. However, the relationship that exists between psychological well-being and hardiness does not indicate a significant difference when the results are being compared among Indonesian remigrants and Indonesian citizens.

Furthermore, the author performed a descriptive analysis of comparison based on international requisite. Variation exists on participants' hardiness based on the reason for their time abroad. The average mean obtained by those who have never been abroad is $4.26(\mathrm{~N}=50)$. Meanwhile, the score obtained by those who have gone abroad for training $(\mathrm{M}=7.33, \mathrm{~N}=3)$, work \& school/university $(\mathrm{M}=4.50, \mathrm{~N}=4)$, husband's job $(\mathrm{M}=3.00, \mathrm{~N}=1)$, work $(\mathrm{M}=2.80, \mathrm{~N}=5)$, school/university ( $\mathrm{M}$ $=2.83, \mathrm{~N}=30)$, accede parents $(\mathrm{M}=3.40, \mathrm{~N}=5)$, school/university \& Study tour $(\mathrm{M}=2.00, \mathrm{~N}=$ 1) and university $(\mathrm{M}=8.00, \mathrm{~N}=1)$. Despite the massive difference in number of participants within the specified groups of international requisite, a mean difference exists between those who went abroad for training, work \& school/university and university and those who have never been abroad where the latter obtained a lower level of hardiness.

Similarly, variation exists on participants' hardiness based on the reason for their time abroad. The average mean obtained by those who have never been abroad is $177.40, \mathrm{~N}=50$ ). Meanwhile, the score obtained by those who have gone abroad for training $(\mathrm{M}=176.0, \mathrm{~N}=3)$, work \& school/university $(\mathrm{M}=198.50, \mathrm{~N}=4)$, husband's job $(\mathrm{M}=196.0, \mathrm{~N}=1)$, work $(\mathrm{M}=188.40, \mathrm{~N}=$ 5), school/university $(M=171.63, N=30)$, accede parents $(M=183.60, N=5)$, school/university \& Study tour $(M=152.0, N=1)$ and university $(M=209.0, N=1)$. Despite the massive difference in number of participants within the specified groups of international requisite, a mean difference between those who went abroad for work, accede parents, husband's job and work \& school/university and those who have never been abroad where the latter obtained a lower level of psychological well-being.

Moreover, a positive significant correlation exists between psychological well-being and age $(\mathrm{r}=.375, \mathrm{p}<.01)$ as well as hardiness and age $(\mathrm{r}=.427, \mathrm{p}<.01)$. Age has a significant impact on psychological well-being and hardiness such that the older the participant, the higher their level of psychological well-being as well as their hardiness. This finding is supported by Bingham \& Stryker (1995)'s theory on socioemotional development. It states that different types of personality develops throughout an individual's lifetime. The formation of previous personality in the earlier developmental stage would be stable until late adulthood. However, the environment in which the individual lives in can affect the formation of these personality characteristics. Thus, it can be said that an individual's international experience (difference in environmental experience) can affect the formation of their personality characteristics.

\section{Conclusions, Implications and Further Recommendations}

Even though there is a significant correlation between psychological well-being and hardiness, no significant difference was found between Indonesian remigrants and Indonesian citizens. Theoretically proven in other studies, psychological well-being can be affected by several factors within the environment such as (1) socioeconomic status, (2) age, (3) rural residence, (4) age of 
marriage and (5) educational attainment (Eggleston et. al, 2001). These are confounding variables that have not been all taken into account by the authors except for age, rural residence and educational attainment.

In addition, it has been stated by Bingham \& Stryker (1995) that personality develops throughout an individual's lifetime. Therefore, the age in which an individual is at plays a major role in their level of hardiness. Moreover, the age at which the individual moved away from their country of origin and settle in a foreign country has an effect on their experience which affects their psychological well-being as well as their hardiness. The developmental stage in which the individual is at has a major impact on their characteristics as well as their quality of life. In conclusion, further research is needed in order to specify and set the right criteria needed to make proper comparison between individuals who have lived abroad and returned to their country of origin and those who have never lived abroad and stayed in their country of origin throughout their lifetime.

\section{References}

[1] Dustmann, C.: Speaking Fluency, Writing Fluency and Earnings of Migrants. Journal of Population Economics, 7(2), 135-156 (1994)

[2] Harker, K: Immigrant Generation, Assimilation, and Adolescent Psychological Well-Being. Social Forces, 79(3), 969-1004 (2001)

[3] Kardum Igor, Hudek-KneževićJasna and KrapićNada. Psychological Topics 21 (2012), 3, 487-507 (2012) https://www.researchgate.net/publication/274958349.

[4] Kwartarini, W.Y.: Going through Acculturation: The cultural experience of Indonesian students living in Germany. Berlin: Lambert Academic Publishing (2010)

[5] Liu, X., \& Zhao, J. Chinese Migrant Adolescents' Perceived Discrimination and Psychological WellBeing: The Moderating Roles of Group Identify and The Type of School. Plos One, DOI:10.1371 (2016)

[6] Lopez, O., Haigh, C,. \& Burney, S.: Relationship Between Hardiness and Perceived Stress in Two Generations of Latin Amrican Migrants (2004)

[7] Merah Putih: Jumlah WNI di Luar Negeri Capai Jutaan Orang. Retrieved 16 January 2015, from http://news.merahputih.com/nasional/2015/03/19/jumlah-wni-di-luar-negeri-capai-jutaanorang/9061/ (2015)

[8] National Geographic Society: What is Human Migration. Retrieved 16 January, from http://www.nationalgeographic.com/xpeditions/lessons/09/g68/migrationguidestudent.pdf(2005)

[9] Nayyeri, M., \& Aubi, S.: Prediction well-being on basic components of hardiness. Social and Behavioral Sciences, 30, 1571-1575 (2011)

[10] Pirvu, R., \& Axinte, G.: Return Migration - Reasons, Consequences and Benefits. Annals of the University of Petrosam. Economics, 12(4), 193-202 (2012)

[11] Ryff, C.D.: Happiness is everything or is it? Exploration on the meaning of Psychological well-being. Journal of Personality and Social Psychology, 57(6), 1069-1081 (1989)

[12] Ryff, C., \& Keyes, C.: The structure of psychological well-being revisited. Journal of Personality and Social Psychology. 69, 719-727 (1995)

[13] Santrock, J. W.: Life-Span Development (13th Ed). New York: McGraw-Hill (2011)

[14] Segal, U.A., \& Mayadas, S.N.: Assesment of Issues Facing Immigrant and Refugee Families. Child Welfare League of America, Vol. LXXXIV, \#5 (2005) 
[15] Seifert, T. The Ryff.: scales of psychological well-being. Retrieved 19 January 2016, from http://www.liberalarts.wabash.edu/ryff-scales/(2005)

[16] Skomorovsky, A., \& Sudom, K.A.: Role of hardiness in the psychological well-being of Canadian forces officer candidates. Military Medicine, 176(1), 7 (2011)

[17] Wang, W. W. \& Fan, C.C.: Succes or Failure: Selectivity and Reasons of Return Migration in Sichuan and Anhui, China. Envionmental and Planning, Vol. 38, pages 939-958 (2006) 